\title{
Resection of the First Rib for Fibrous Dysplasia by Transmanubrial Approach
}

\author{
Ints Silins*, Ilze Simanovica**, Ilga Rone*** \\ *Department of Thoracic Surgery, Clinic of TB and Lung Diseases, Latvia \\ **Department of Radiology, Clinic of TB and Lung Diseases, Latvia \\ ***Department of Pathology, Riga Eastern Clinical University Hospital, Latvia
}

\section{Summary}

Primary tumours of the first rib remains a rarity, but the diagnosis and the surgical approach are quite challenging because of the anatomical difficulties in approaching it and the closeness of subclavian vessels. The anterior transmanubrial approach gives an excellent exposure, especially when approaching the anterior part of the first rib. Diagnosis quite often can be approved just by the histo-pathological examination of the resected specimen. We describe the management of such a case, when diagnosis of fibrous dysplasia was confirmed postoperatively.

Key words: resection of first rib, anterior transmanubrial approach, thoracic inlet, fibrous dysplasia.

\section{AIM OF THE DEMONSTRATION}

The aim of this demonstration is to show the transmanubrial anterior approach we used for the resection of the first rib in the patient with the preoperatively unknown lesion.

\section{CASE REPORT}

A thirty two year-old female patient had complaints of discomfort in the right shoulder and the apex of chest for about one year period. CXR and CT performed on the ambulatory basis revealed the enlargement and the change in the structure of the first rib on the right (Fig.1). The patient was sent to our clinic with the suspicion of tumour for the evaluation for a surgical treatment. On the contrasted CT examination we revealed that the anterior portion of the first rib on the right was enlarged with cystic changes in its structure, but well conturated and the subclavian vessels were not involved in the process (Fig.2, 3). The diagnosis of the fibrous dysplasia was suspected, but the possibility of a tumour could not be excluded. We decided to perform a surgical resection by the anterior transmanubrial approach as described by Grunnenwald (3) for better visualisation and controlling of subclavian vessels. It is made by a L-shaped incision on the neck anteriorly of a sternocleidoid muscle curving over the manubrium of sternum towards the upper part of the chest wall bellow the clavicle in the level of the first intercostal space. The L-shaped section of the manubrium allows us to leave the clavicle and the claviculo-sternal joint intact in the contrary to other transclavicular approaches (Fig.).

The pathological examination of the resected rib confirmed the diagnosis of the fibrous dysplasia of the rib (Fig.5, 6).

\section{DISCUSSION}

There are different approaches used for approaching the thoracic inlet which is presented with surgically challenging anatomical structures $(1,5,6)$. The classical postero-lateral thoracotomy approach described by Paulson is recommended for the posterior part of the thoracic inlet. It is possible to resect the first rib by transaxillary approach or even by VATS approach (2) as described by some authors for the treatment of thoracic outlet syndrome. However for the problems in the anterior part of the thoracic inlet different anterior approaches are recomended. The most aggressive is hemi-Clamshell approach which gives an excellent exposure, but it is very aggressive and traumatising. Different modifications of transclavicular approaches are offered, but all of them influence the upper girdle function and leave the pain in the shoulder $(1,5,6)$. The transmanubrial approach with a L-shape incision of the manubrial part of sternum provides quite a good visualisation of the subclavian vessels, but leaves intact a sternoclavicular joint. Therefore it presents advantages in cosmetics and the functional ability of a shoulder $(2$, $3,5)$.

The diagnosis of the fibrous dysplasia is mostly made on the basis of CT examination and surgical treatment is not even necessary, especially if a patient is asymptomatic. The fibrous dysplasia is a non-neoplastic lesion what is characterized by fibrous replacement of the medullary cavity of the rib and mostly presented as a solitary lesion. It equally affects both sexes. If symptoms occur or no malignancy can be excluded, the surgical excision is recommended (6).

Conflict of interest: None 


\section{REFERENCES}

1. Dartevelle PG, Chapelier AR, Macchiarini P, Lenot B, Cerrina J, Ladurie FL, Parquin FJ, Lafont D. Anterior transcervical-thoracic approach for radical resection of lung tumors invading the thoracic inlet // J Thorac Cardiovasc Surg, 1993;105(6):1025 - 1034

2. Di Rienzo G, Surrente C, Lopez C, Urgese AL. Transmanubrial osteomuscular sparing approach: different indications // Interactive CardioVascular and Thoracic Surgery, 2010; 11:482-484

3. Grunenwald D, Spaggiari L. Transmanubrial osteomuscular sparing approach for apical chest tumors // Ann Thorac Surg, 1997; 63(2):563 - 566

4. Truin W, Siebenga J, Belgers E, Bollen ECM. The role of video-assisted thoracic surgery in the surgical treatment of superior sulcus tumors // Interactive CardioVascular and Thoracic Surgery, 2010; 11: $512-514$

5. Vanakesa T, Goldstraw P. Antero-superior approaches in the practice of thoracic surgery // Eur J Cardiothorac Surg, 1999; 15(6):774-780

6. Vanecko RM, Shields TW. Anterior Transthoracic Approaches to the Spine // In: Shields TW, Lo Cicero III J, Ponn RB. General Thoracic Surgery. $5^{\text {th }}$ ed. Lippincott Williams \& Wilkins 1999; 592

\section{Address:}

Ints Silins

Department of Thoracic Surgery

Clinic of TB and Lung Diseases

State Agency "Latvian Centre of Infectology"

Upeslejas, Stopinu novads, LV-21 18, Latvia

E-mail: ints.silins@lic.gov.lv

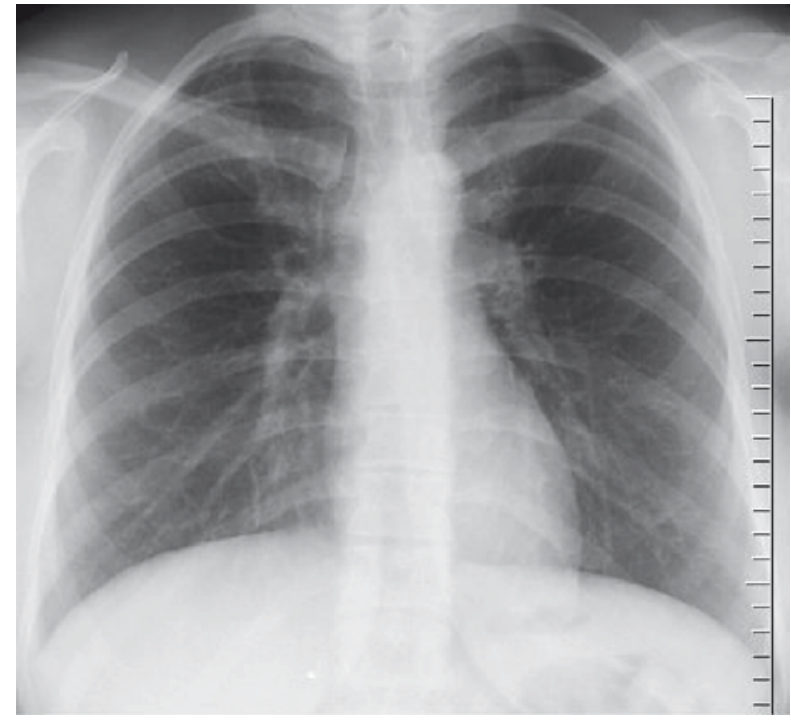

Fig. 1. The chest $\mathrm{X}$-ray on the presentation showing the enlargement of the first rib on the right

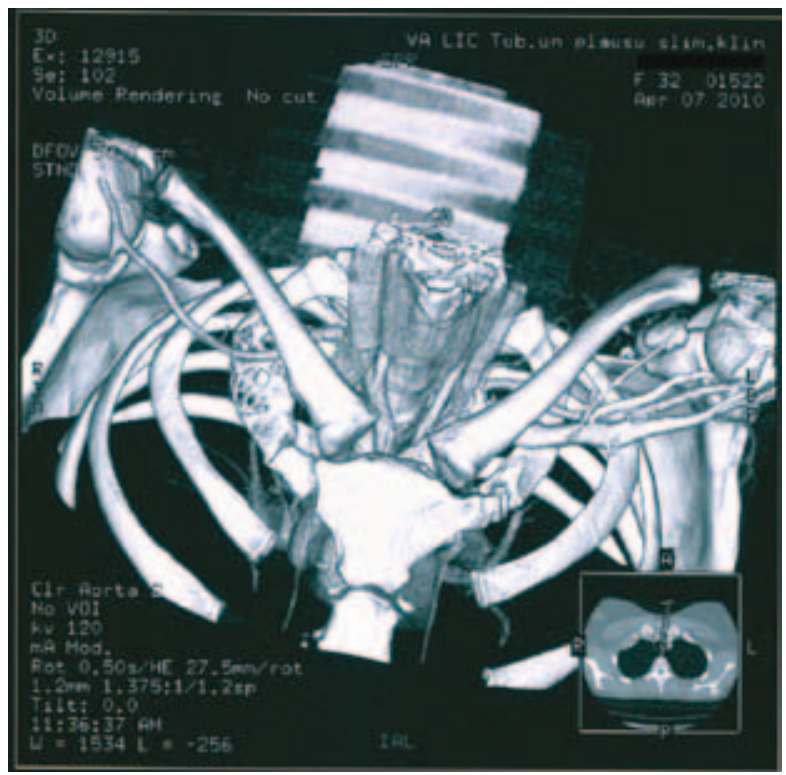

Fig. 2. The computed tomography in 3D reconstruction 


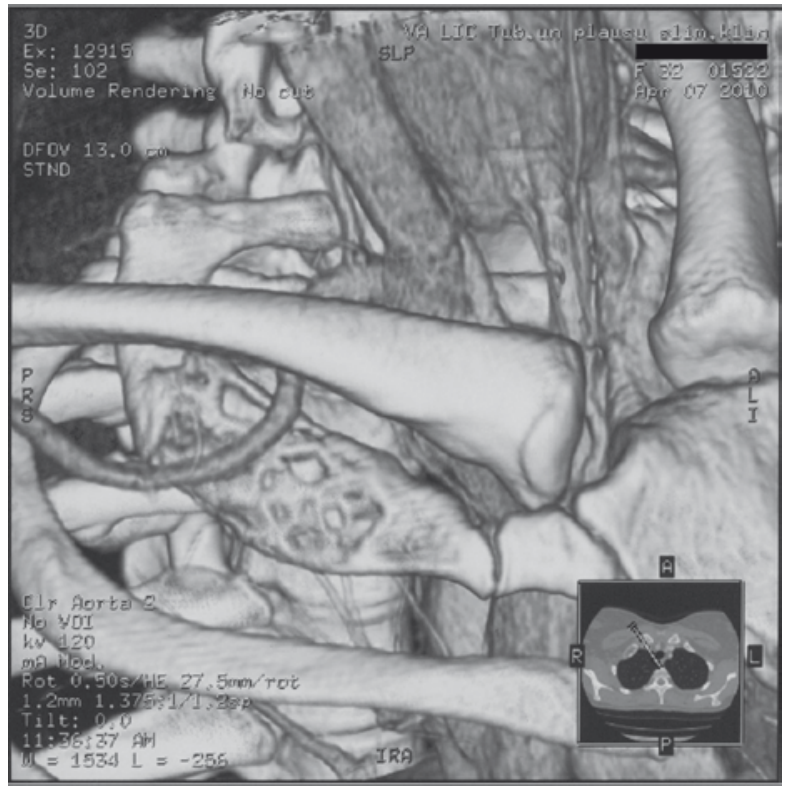

Fig. 3. More closer view of the contrasted CT reconstruction showing the intact subclavian artery and small additional branches from it to the affected part of the first rib

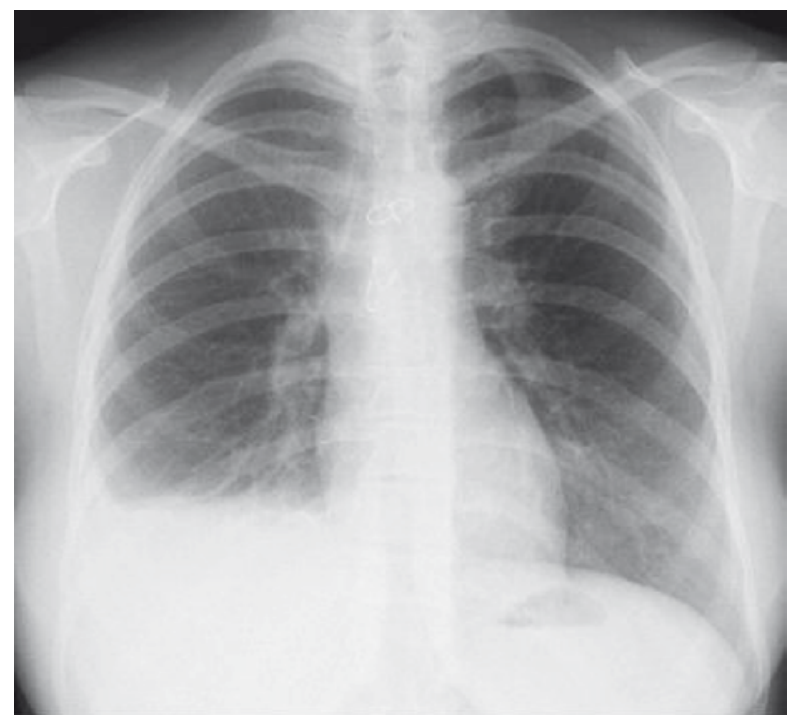

Fig. 4. The chest $X$-ray after the operation showing the absence of the affected anterior part of the first rib on the right and steel sutures in the place of the reattached manubrial part of sternum

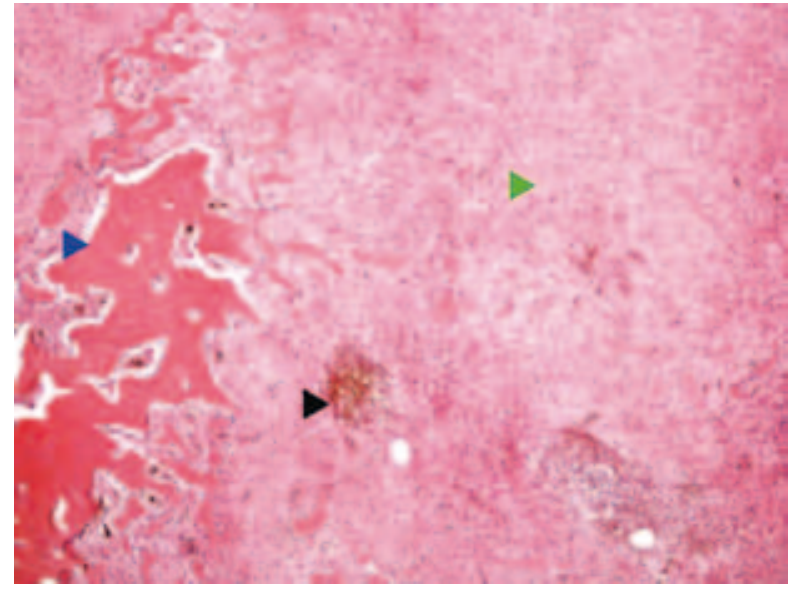

Fig. 5. The histo-pathological examination of the resected rib showing the proliferation of fibrous tissue replacing bony tissue [HE stain; 100x magnification]

blue arrow - bone;

green arrow - fibrous tissue;

black arrow - perivascular lymphocitary infiltrate;

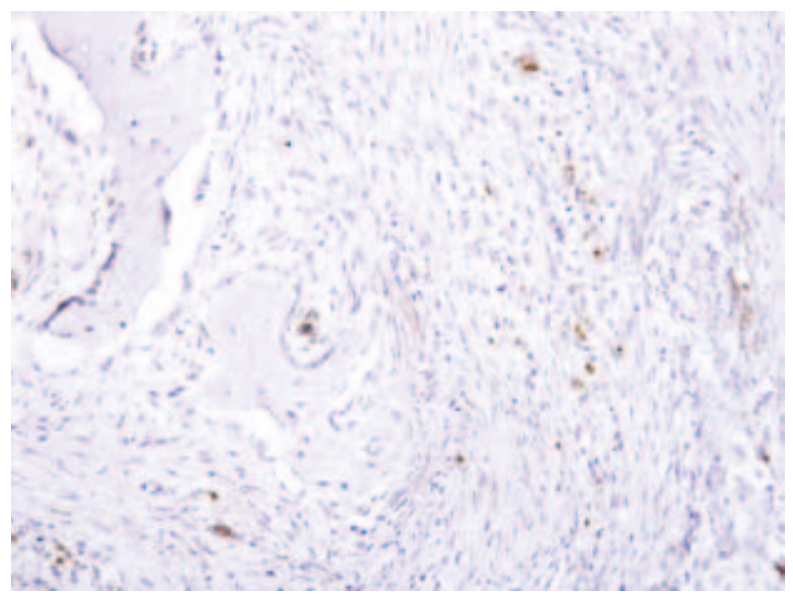

Fig. 6. The immuno-histo-chemical examination [Ki-67 stain; 400x magnification] showing low proliferative activity of cells 